\title{
Study on Comparative Histology of Retinas in Ctenopharyngodon idella, Cynops orientalis, Bufo bufo gargarizans, Gekko japonicus, and Columba livia
}

\author{
Estudio Histológico Comparado de la Retina en Ctenopharyngodon Idella, \\ Cynops Orientalis, Bufo Bufo Gargarizans, Gekko Japonicus, y Columba Livia
}

Qiusheng She*; Zhenqiang An"*; Chengqiang Xia ${ }^{* * *}$; Yunfei Kong* \& Enxiang Chen ${ }^{* * * * *}$

SHE, Q.; AN, Z.; XIA, C; KONG, Y. \& CHEN, E. Study on comparative histology of retinas in Ctenopharyngodon idella, Cynops orientalis, Bufo bufo gargarizans, Gekko japonicus and Columba livia. Int. J. Morphol., 32(3):918-922, 2014.

SUMMARY: The objective of this study was to explore the relationship between the retinal structure and its life adaptation to the environment of Ctenopharyngodon idella, Cynops orientalis, Bufo bufo gargarizans, Gekko japonicus and Columba livia . Measuring retinal thickness of each layer, the nuclei layer, and the diameter of each nuclear layer of the five animals, the statistical data analysis shows that: the nuclei layers of five animals are all 4, and their structures can be divided to 10 layers when observing with optical microscope. The retinal thickness of Ctenopharyngodon idella was $190.49 \mathrm{~mm}$, Cynops orientalis was $173.07 \mu \mathrm{m}$, and the Bufo bufo gargarizans was $195.06 \mu \mathrm{m}$, Gekko japonicus was $224.32 \mu \mathrm{m}$ and Columba livia was $174.10 \mu \mathrm{m}$. The number of retinal inner nuclear layers of Bufo bufo gargarizans and Gekko japonicus and Columba livia are more than their outer nuclear layers, on the contrary, retinal inner nuclear layers of Ctenopharyngodon idella and Cynops orientalis are less than their outer nuclear layers. The rod and cone layer of retina of Cynops orientalis were more advanced, but their nerve fiber layer (NFL) degraded highly, revealing a strong photosensitivity but a low visual sensitivity; to Columba livia, their NFL of retina are highly developed, so as their vision. The different structures and functions of the retina of Ctenopharyngodon idella, Cynops orientalis, Bufo bufo gargarizans, Gekko japonicus and Columba livia correspond with their behavioral characteristics and the living environment's change from aquatic to amphibious to land.

KEY WORDS: Ctenopharyngodon idella; Cynops orientalis; Bufo bufo gargarizans; Gekko japonicas; Columba livia ; Retina; Comparative histology.

\section{INTRODUCTION}

There have been some reports about research on the morphology, structure as well as functions of animal retinas (Zhang \& Jia, 2003; Zheng \& Zhang, 2005; Zhang et al., 2007). Zhang \& Jia made comparative studies on microstructure of retinas for 5 species of lacertillia in 2003, Zheng \& Zhang observed and compared microstructure of retinas for Batrachuperus tibetanus and Rana guadranus in 2005, and Zhang et al. made the histological observation and comparison on the retina of Chrysolophus pictus and Jspalura splendida in 2007. All these research results show that there are some differences between animal retinal structures, which are adaptive to their habitats and life styles. This paper selects and makes a comparison to Ctenopharyngodon idella, Cynops orientalis, Bufo bufo gargarizans, Gekko japonicus, and Columba livia in accordance with the evolutionary relationship of vertebrates from aquatic animals to amphibians to reptiles and then to birds, in order to understand the evolutionary characteristics of retinal histology in these five kinds of animals and accumulate relative data on morphology and histology for the research on animal retinal system development as well as ophthalmology.

\section{MATERIAL AND METHOD}

We collected Ctenopharyngodon idella and Bufo bufo gargarizans from Bai Guishan Reservoir Wetland, Ping Dingshan city; Cynops orientalis from Jigongshan, Xinyang

\footnotetext{
Departement of Bioengineering, Henan University of Urban Construction, Pingdingshan467036, Henan province ,People's Republic of China.

** Marine Biology Institute \& Guangdong Provincial Key Laboratory of Marine Biology,Shantou University, Shantou515063,Guangdong ,People's Republic of China.

${ }^{* * *}$ State Key Laboratory of Microbial Technology,Shandong University, Jinan 250100,Shandong province, People's Republic of China.;

${ }^{* * * * *}$ State Key Laboratory of Silkworm Genome Biology, Southwest University, Chongqing 400715, People's Republic of China).
} 
city, Henan Province; Gekko japonicus from Ye County, Ping Dingshan city; Columba livia were purchased from downtown, Ping Dingshan city.

Ten samples from each kind of animals are taken regardless of sex, and their left eyes were removed. After anaesthetizing and killing these animals, eyeballs were fixed in Bouin's solution, then the part extremely near the center front and rear the animals' retina was transected, and conventional paraffin sections were made. The thickness of the sections was $7 \mu \mathrm{m}$ and by H-E staining; fluorescence inverted microscope (Nikon ECLIPSE TE2000-U) was used to observe, photograph as well as to measure them, and measured data was analyzed with T-test by SPSS17.0 software.

\section{RESULTS AND DISCUSSION}

The basic morphological characteristics of animal samples. Is shown in Table I.

Table I. The basic morphological characteristics of Ctenopharyngodon idella, Cynops orientalis, Bufo bufo gargarizans, Gekko japonicus and Columba livia.

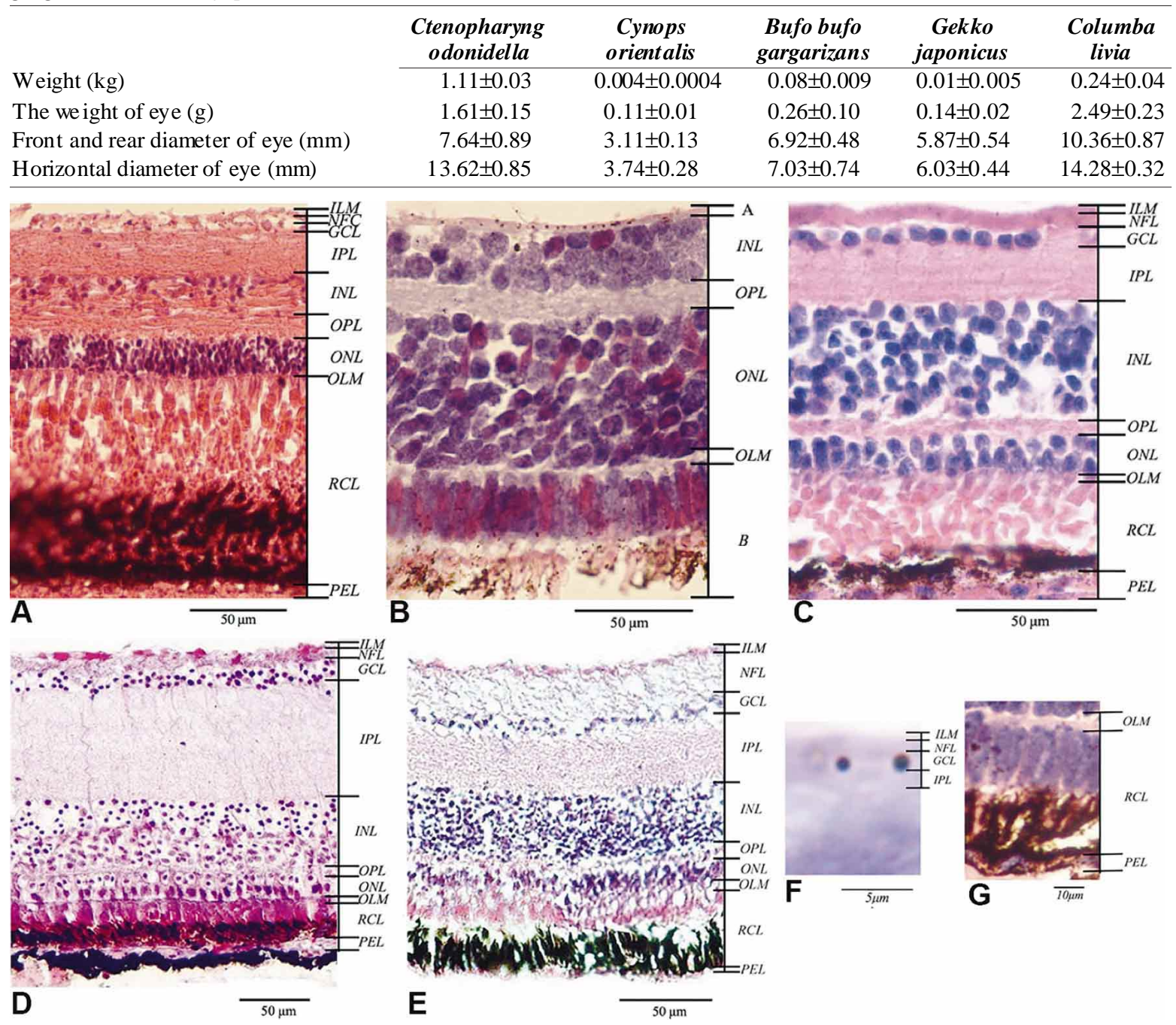

Fig. 1. Comparative observation of transverse section about five kinds of animal's retinal structures. A. The retina in transverse section of Ctenopharyngodon idella (40x10); B. The retina in transverse section of Cynops orientalis (40x10); C. The retina in transverse section of Bufo bufo gargarizans (40x10); D. The retina in transverse section of Gekko japonicas (40x10); E. The retina in transverse section of Columba livia (40x10); F. Present the part A of transverse section in image B of this figure, and G. Present the part B of transverse section in image B of this figure. PEL= pigment epithelium layer; RCL $=$ rods and cones layer; $\mathrm{OLM}=$ outer limiting membrane; $\mathrm{ONL}=$ outer nuclear layer; $\mathrm{OPL}=$ outer plexiform layer; $\mathrm{INL}=$ inner nuclear layer; IPL= inner plexiform layer; $\mathrm{GCL}=$ ganglion cell layer; $\mathrm{NFL}=$ nerve fibers layer and $\mathrm{ILM}=$ inner limiting membrane. 


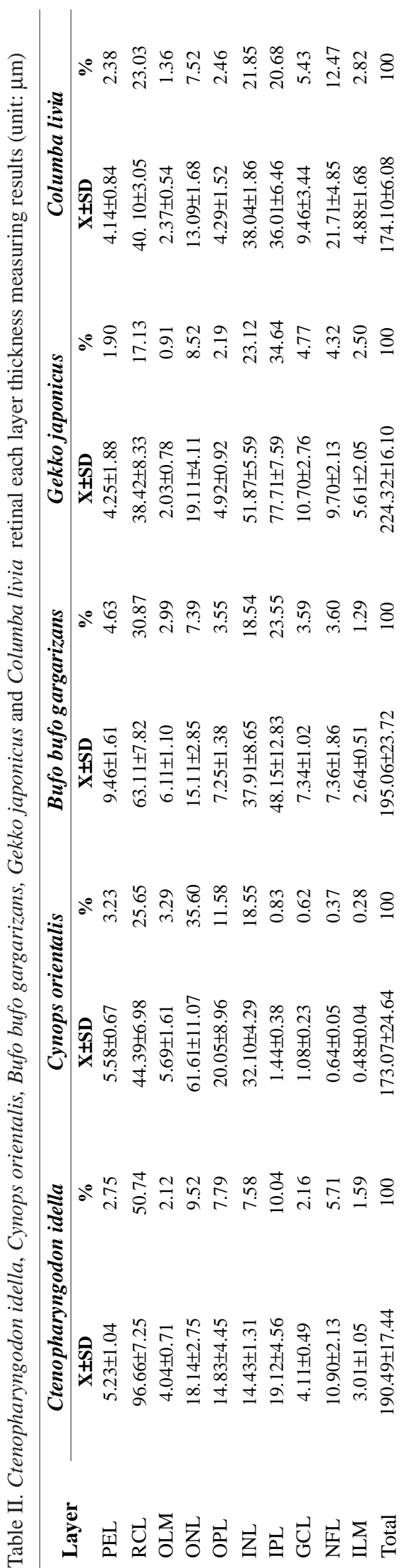

Retinal histological structure characteristics of animal samples. The retinal histological structures of Ctenopharyngodon idella, Cynops orientalis, Bufo bufo gargarizans, Gekko japonicus, and Columba livia are shown in Figure 1. They resemble each other, from the outside to the inside are divided into 10 layers, which are listed as follows: pigment epithelial layer (PEL), rod and cone layer (RCL), outer limiting membrane (OLM), outer nuclear layer (ONL), outer plexiform layer (OPL), inner nuclear layer (INL), inner plexiform layer (IPL), ganglion cell layer (GCL), nerve fiber layer (NFL), and inner limiting membrane (ILM). In the 5 kinds of animals, all the central parts of retina are thick while the surrounding parts are thin.

The result of measuring each layer thickness in five animals retina can be seen in Table II, and the measured data are analyzed with T-test by SPSS17.0 software, shown in Table III.

The measurement results of retinal histological structures in each animal sample show that: (i) It can be seen from the ratio of the thickness of rod and cone layer accounting for the total thickness of retina (the respective ratio of Ctenopharyngodon idella, Cynops orientalis, bufo bufo gargarizans, Gekko japonicas, and Columba livia is 50.74\%, 25.65\%, $30.87 \%, 17.13 \%$ and $23.03 \%$ ) that photosensitivity of Gekko japonicas, Columba livia, Cynops orientalis, Bufo bufo gargarizans and Ctenopharyngodon idella is enhanced in sequence. (ii) In the retinas, the INL and IPL constitute the secondary neurons, while the GCL and NFL form the third neurons. The NFL is closely related to visual development degree.

In the measurement results, the respective proportions of NFL in each animal sample accounting for retinas are $0.37 \%$ (Cynops orientalis), $3.60 \%$ (Bufo bufo gargarizans), $4.32 \%$ (Gekko japonicas), $5.71 \%$ (Ctenopharyngodon idella) and $12.47 \%$ (Columba livia), and the proportion reveals a gradual increasing trend, which shows that the development degree of the visual sense of these animals increases gradually.

The comparison of retina between each nuclei layer and the diameter. The cell nuclei of each nuclear layer near the central portion of retinal front and rear axle was observed in 5 kinds of animals under the microscope, statistical analysis on the layer number of cell nuclei in 3 nuclear layers was carried out and the diameters of cell nuclei measured. The results are shown in Table IV. The results show that: (i) The layer number of cells in retinal inner nuclear layer of Bufo bufo gargarizans, Gekko japonicus and Columba livia is more than that in outer nuclear layer and the layer number of cells in outer nuclear layer is more than that in ganglion cells. That retinal structure achieves the aims that multiple input signals of visual cells gather to a ganglion cell, so that each ganglion cell has a larger receptive field so as to improve the light sensitivity as well as visual sensitivity (Zhang \& Jia; Zheng \& Zhang) and to adapt to the terrestrial or crepuscular predatory activities; (ii) the maximum layer number in outer nuclear layer of Cynops orientalis is 6 to 9 and its thickness accounts for the largest proportion of retina (35.60\%) with largest nuclei diameter $(8.45$ $\mu \mathrm{m}$ ), while the diameter of cell nuclei in inner nuclear layer is $8.78 \mu \mathrm{m}$; the outer nuclear layer of Ctenopharyngodon idella is divided into 5 to 6 


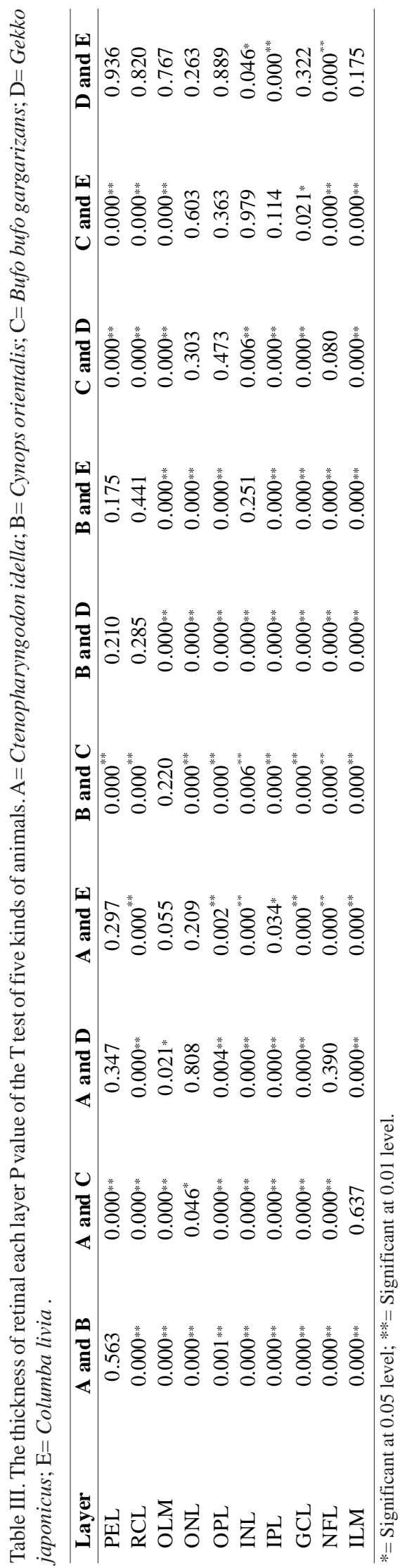

layers, and it has the least number of inner nuclear layer (2 to 3 layers) while its thickness accounts for the least proportion in retina (7.58\%). It has the highest degree of photosensitivity and lower degree of visual sensitivity, which are suitable to nocturnal activities; the layer number in inner nuclear layer of Bufo bufo gargarizans is 5 to 8, the diameter of cell nuclei $(5.11 \mu \mathrm{m})$ is smaller than that of Cynops orientalis and the diameter of nuclei in outer nuclear layer is $5.31 \mu \mathrm{m}$; the layer number in inner nuclear layer of terrestrial Gekko japonicus is 8 to 9 and the outer nuclear layer is 2 and the ganglion cell layer is divided into 2 layers; the cells in outer nuclear layer of Columba livia are small with high density and the inner nuclear layer is divided into 8 to 10 layers, therefore, the capability of receiving visual information and analyzing visual information is enhanced with a high degree of visual resolving power, which lays the structural foundations for their reliance on visual terrestrial predation (She et al., 2011).

\section{CONCLUSIONS}

Through the observation and measurement, statistical analysis as well as comparative study of retinal histological structures in Ctenopharyngodon idella, Cynops orientalis, Bufo bufo gargarizans, Gekko japonicus and Columba livia, the paper draws the following conclusions: Ctenopharyngodon idella has more outer nuclear layers and the least inner nuclear layers with its thickness accounting for the least proportion in retina, furthermore, it has the highest degree of photosensitivity and lower degree of visual acuity, which is suitable to crepuscular activities; Cynops orientalis has the most outer nuclear layers, whose nuclei diameter is also the largest, and its thickness accounts for largest proportion, while it has largest nuclei diameter of inner nuclear layer and less number of layers, which is close to Ctenopharyngodon idella. Its nerve fiber layer degrades highly with lower visual sensitivity and extremely strong photosensitivity, which forms the lifestyle of relying on olfactory sense to prey in weak light environment; Bufo bufo gargarizans has less outer nuclear layers with larger diameter of cell nuclei, while it has more inner nuclear layers, hence it has strong photosensitivity and weak visual sensitivity, which is suitable to crepuscular activities; Gekko japonicus has fewer outer nuclear layers with small diameter of cell nuclei while it has more outer nuclear layers with its thickness accounting for the largest proportion. It has strong photosensitivity as well as strong visual sensitivity, hence it is suitable to crepuscular activities; retinal histology of Columba livia has small cells in the outer nuclear layer and many layers in inner nuclear layer with the thickness of IPL accounting for large proportion and nerve fiber layer developed highly, and it has strong capability of receiving and analyzing visual information. It has a high degree of tolerance to strong light as well as strong visual resolving power, and it is suitable to terrestrial flying life.

To sum up, the retina of Ctenopharyngodon idella is suitable for nocturnal activities; the retina of Cynops orientalis has strong photosensitivity but weak visual sensitivity, and its lifestyle is nocturnal, furthermore, it mainly relies on olfactory sense for predation; the retina of Bufo bufo gargarizans and Gekko japonicus is suitable for nocturnal and 
Table IV. The comparison between retinal nuclei layer and the diameter to Ctenopharyngodon idella, Cynops orientalis, Bufo bufo gargarizans, Gekko japonicus and Columba livia

\begin{tabular}{lcccccc}
\hline & \multicolumn{2}{c}{ GCL } & \multicolumn{2}{c}{ INL } & \multicolumn{2}{c}{ ONL } \\
\cline { 2 - 7 } & $\begin{array}{l}\text { Nuclei } \\
\text { layer }\end{array}$ & $\begin{array}{c}\text { Nuclei diameter } \\
(\boldsymbol{\mu m})\end{array}$ & $\begin{array}{c}\text { Nuclei } \\
\text { layer }\end{array}$ & $\begin{array}{c}\text { Nuclei diameter } \\
(\boldsymbol{\mu m})\end{array}$ & $\begin{array}{c}\text { Nuclei } \\
\text { layer }\end{array}$ & $\begin{array}{c}\text { Nuclei diameter } \\
(\boldsymbol{\mu m})\end{array}$ \\
\hline Ctenopharyngodon idella & 1 & 2.40 & $2 \sim 3$ & 2.57 & $5 \sim 6$ & 2.47 \\
Cynops orientalis & 1 & 1.08 & 3 & 8.78 & $6 \sim 9$ & 8.45 \\
& & 5.11 & $5 \sim 8$ & 4.53 & 2 & 5.31 \\
Bufo bufo gargarizans & 1 & (the round nuclei) & & (the round nuclei) & (the round nuclei) \\
& & $7.15 / 4.55$ & & $6.61 / 3.78$ & $7.68 / 4.47$ \\
Gekko japonicus & & (the oval nuclei) & & (the oval nuclei) & (the oval nuclei) \\
Columba livia & 2 & 3.56 & $8 \sim 9$ & 3.30 & 2 & 3.64 \\
\hline
\end{tabular}

crepuscular activities; the retina of Columba livia accommodates to diurnal terrestrial flying life which can tolerate strong light.

SHE, Q.; AN, Z.; XIA, C; KONG, Y. \& CHEN, E. Estudio histológico comparado de la retina en Ctenopharyngodon idella, Cynops orientalis, Bufo bufo gargarizans, Gekko japonicus, y Columba livia. Int. J. Morphol., 32(3):918-922, 2014.

RESUMEN: El objetivo de este estudio fue explorar la relación entre las estructuras de la retina y su adaptación al medioambiente en Ctenopharyngodon idella, Cynops orientalis, Bufo bufo gargarizans,Gekko japonicus y Columba livia . La medición del espesor de cada capa de la retina, la capa nuclear y su diámetro en los cinco animales, mostró a través del análisis estadístico que las capas nucleares en todos ellos fueron 4, y sus estructuras se pueden dividir en 10 capas cuando se observan con el microscopio óptico. El espesor de la retina de Ctenopharyngodon idella fue 190,49 $\mu \mathrm{m}$, de Cynops orientalis fue 173,07 $\mu \mathrm{m}$, de Bufo bufo gargarizans fue 195,06 $\mu \mathrm{m}$, de Gekko japonicus fue 224,32 $\mu \mathrm{m}$ y de Columba livia fue $174,10 \mu \mathrm{m}$. El número de capas nucleares internas de la retina de Bufo gargarizans, Gekko japonicus y Columba livia fue mayor que sus capas nucleares externas, mientras que las capas nucleares internas de Ctenopharyngodon idella y Cynops orientalis fueron menos que las capas nucleares externas. La capa de conos y bastones de la retina de Cynops orientalis fue más desarrollada, pero su capa de fibras nerviosas presentó una elevada degeneración, lo que muestra una gran fotosensibilidad, pero una sensibilidad visual baja. En Columba livia, la capa de fibras nerviosas de la retina estuvo muy desarrollada, y de esta manera, su visión. El grado de desarrollo de las diferentes estructuras y funciones de la retina de Ctenopharyngodon idella, Cynops orientalis, Bufo bufo gargarizans, Gekko japonicus y Columba livia está relacionada con sus características de comportamiento y el cambio de las condiciones de las vidas acuática y anfibia en la tierra.

PALABRAS CLAVE: Ctenopharyngodon idella; Cynops orientalis; Bufo bufo gargarizans; Gekko japonicas; Columba livia ; Retina; Histología comparada.

\section{REFERENCES}

She, Q-S.; Xie, Z-H.; Chen, E-X.; Tian, X. \& Chen, L-Y. Study of the Comparative Histology of Retina for Carassius auratus, Rana nigromaculata and Oryctolagus cuniculus domestica. Sichuan J. Zool., 30(5):800-4, 2011.

Zhang, Y. \& Jia, L. Comparative studies on microstructure of retinas for 5 species of Lacertillia. J. Northwest Univ. (Nat. Sci. Ed.), 33(4):475-7, 2003.

Zhang, J.; Yu, S-Y.; Yang, W-J.; Chen, Y-Q.; Shang, J-K.; Zhang, H-L. \& Xie, M-R. Histological observation on the retina of chrysolophus pictus and Jspalura splendida. Chin. J. Zool., 42(4):112-6, 2007.

Zheng, X. \& Zhang, Y. Comparative on microstructure of retinas for Batrachuperus tibetanus and Rana guadranus. J. Shaanxi Norm. Univ. (Nat. Sci. Ed.), 33(1):99-101, 2005.

Correspondence to:

Dr. Qiusheng She

Department of Bioengineering

The School of Life Science and Engineering

Henan University of Urban Construction

Daxiangshan road

Xin Cheng Area

Pingdingshan 467036, Henan Province

PEOPLE'S REPUBLIC OF CHINA

Email: sheqiusheng828@163.com

Received: 20-01-2014

Accepted: 27-06-2014 